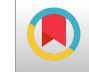

\title{
Psychiatric Disorders Comorbidity in Two General Medical Hospitals in Iran Between 2014 - 2015
}

\author{
Forouzan Elyasi ${ }^{1,2,{ }^{*}, \text { Marzieh Azizi }}{ }^{3,4}$, Sina Sabourian Joubari ${ }^{3,4}$ and Seyyed Hessam Mirani ${ }^{4}$ \\ ${ }^{1}$ Department of Psychiatry, Collage of Medicine, Mazandaran University of Medical Sciences, Sari, IR Iran \\ ${ }^{2}$ Psychiatry and Behavioral Sciences Research Center, Sexual and Reproductive Health Research Center,Addiction Institute, Mazandaran University of Medical Sciences, Sari, \\ IR Iran \\ ${ }^{3}$ Master of Counseling in Midwifery, Student Research Committee, Mazandaran University of Medical Sciences, Sari, IR Iran \\ ${ }^{4}$ Nasibeh Nursing and Midwifery Faculty, Mazandaran University of Medical Sciences, Sari, IR Iran \\ "Corresponding author: Department of Psychiatry, School of Medicine, Mazandaran University of Medical Sciences, Razi Avenue, Emam Khomeini General Hospital, Sari, Iran. \\ Tel: +98-9111551097, Fax: +98-1133363754, Email: forouzan.el@gmail.com
}

Received 2017 February 05; Revised 2017 March 16; Accepted 2017 August 10.

\section{Abstract}

Background: Although there is a high prevalence of psychiatric comorbidities in patients in general medical hospitals, they have remained undiagnosed in some cases.

Objectives: This study was conducted to determine the psychiatric disorders comorbidity of patients in two general medical hospitals in Iran.

Methods: This cross-sectional descriptive study was conducted in Imam Khomeini and Bu Ali Sina general university hospitals, in Sari, Northern Iran, and included 1,688 patients from different wards of these hospitals. Data were collected via a demographic questionnaire.

Results: With regard to frequency distribution, according to age group and gender, the most consultations (393; 23.3\%) were in the 20 - 29 year's age group and 935 (55.4\%) cases were female. The highest number of consultation cases had been referred from the emergency wards (34\%), followed by the neurosurgery (14.2\%) and internal medicine wards (14.2\%). Psychological assessment was the most common reason for requesting a consultation (26.8\%). In addition, the results indicated that mood disorder (22.3\%) was the most prevalent psychiatric diagnosis.

Conclusions: In order to improve the trend of psychiatric diagnosis in general hospitals, psychiatric liaison staff should be trained in multiple consulting roles, and must improve their skills in addressing inpatient and outpatient treatment. Moreover, other nonpsychiatric physicians should increase their knowledge of attitude toward and psychosocial aspects of medical disorders.

Keywords: Consultation-Liaison Psychiatry, General Hospital, Psychiatric Consultation, Psychiatric Disorders

\section{Background}

The high prevalence of psychiatric comorbidities in medical patients in general hospitals is a huge worldwide problem $(1,2)$. However, a large proportion of these comorbidities remain undetected and underdiagnosed (3, 4). One study suggested that there are two major reasons for this: The situation in which medical staff work and their fears of rejection with regard to enquiries of patient's psychological responses to disease (5). The majority of the studies have shown that a large proportion of patients with somatic diseases simultaneously suffer from psychiatric disorders that slows down the improvement of both diseases (6-9). The pathways that lead to comorbidity of mental and medical disorders are complex and twoway (10). The simultaneous existence of mental and med- ical conditions leads to increased symptom burden, functional impairment, reduced patient quality of life and increased illness costs, a lack of response to treatment $(9,11)$, a higher number of medical readmissions, increased hospital length of stay $(8,12,13)$, and increased mortality rates (7).

A previous study has reported that a third of patients who had a psychiatric consultation were assessed as having no need for any particular psychiatric services. This indicates that these patients were wrongly referred to psychiatric services because of an incorrect diagnosis by their referring physician (6). Several studies have shown that only a small proportion of inpatients with psychiatric comorbidities are referred to psychiatric services, such as psychiatric consultation or psychiatric wards $(5,14)$. According to an epidemiological study that used standardized in- 
struments for diagnosis, the prevalence of psychiatric disorders in inpatients in a general medical setting ranges from $41.3 \%$ to $46.5 \%$ (15). Depression was the most common psychiatric disorder in all groups of organic disease in numerous studies, accounting for $23 \%$ - $37 \%$ of all psychiatric diagnoses $(4,16,17)$. Anxiety neurosis $(18.6 \%)$ as well as drug abuse and dependence (13.8\%) were the next most frequently observed psychiatric disorders $(16,18)$. However, other studies observed that mood disorders, adjustment, and cognitive disorders were the major diagnoses that consultants encountered in consultation-liaison services (13). There has been considerable development in general hospitals and medical setting psychiatry, with a steady increase in the use of health services for the treatment of psychiatric disorders (19). The organizational basis for psychiatric consultation in a general setting is the consultation, or liaison, service (13, 20-22).

Over the past two decades, psychiatric research has shown that consultation-liaison psychiatry (CLP) is used as a bio-psychosocial holistic approach (23) to evaluate, treat, and manage a variety of psychiatric disorders in patients who have been admitted to a general hospital (24). The availability of facilities for consultation-liaison services varies significantly from one country to another (17, 24). The role of psychiatrists in the general hospital and general medical setting has attracted increasing attention in the past decade (21). It is apparent that a CLP service has multiple particular functions $(2,22)$, for example, performing psychiatric consultations at the request of medical physicians (25), holding a patient in the emergency ward, involuntary hospitalization of patients, assessment of patients who have attempted suicide or homicide or who have suicidal or homicidal ideation (21), and identification as well as use of appropriate management of mental conditions (18). The CLP approach results in a variety of benefits (4), such as a reduction in the cost of medical care (26), significantly reduced morbidity and mortality rates, increased case identification, and earlier psychiatric intervention. Finally, it leads to a remarkable decrease in the need to transfer patients to psychiatric facilities (8).

Psychiatric consultation is usually requested for the following reasons: Concern with regard to a patient's diagnosis or patient difficulty in coping with the disorder diagnosed (27), to assist in making a differential diagnosis between organic and psychical pathologies (21), continuation of a patient's complaints or problems, assessment of patients with suicidal or homicidal ideation or a history of previous suicide attempts (28), evaluation of patients with a first diagnosis of a psychiatric disorder, a previous psychiatric history, or who are using psychotropic medications (8), examination of a patient who wishes to die, a patient in an emergency situation (8), evaluation of a patient with known or suspected substance and drug abuse (2), and in cases involving refusal of operation, medication, or treatment (28). The frequency of psychiatric morbidities in non-psychiatric wards in a general setting remains unconfirmed (29). Although the patterns of psychiatric consultations conducted by CLP in Iran have been studied, studies had limited sample sizes and they assess consultation only for several months rather than for a year $(9,11,24)$. Therefore, the present study aimed to determine the psychiatric disorders comorbidity of patients in two general medical hospitals in Sari, Mazandaran, Northern Iran, in 2014 - 2015.

\section{Objectives}

This study was conducted to determine the psychiatric disorders comorbidity of patients in two general medical hospitals in Iran.

\section{Materials and Methods}

\subsection{Procedures}

This cross-sectional, descriptive study was conducted in 2014 - 2015 in Imam Khomeini and Bu Ali Sina general hospitals, which are located in Sari, Northern Iran. The participants were 1,688 patients on different wards (emergency, oncology, gynecology, urology, orthopedics, intensive care unit, internal medicine ward, and neurosurgical) of these hospitals, who had been referred for psychiatric consultation. There were 32,474 admissions to Imam Khomeini and Bu Ali Sina hospitals between April 2014 and March 2015, with the psychiatric consultation rate being $4.06 \%$ among all admissions. Consultations were carried out by senior residents, who were either accompanied by their professors or under their supervision. Cases were selected via easy sampling. Inclusion criteria were all patients admitted to the wards of the two general hospitals between April 2014 and March 2015. We excluded the consultation that the diagnosis of illness is not mentioned by psychiatrists or assistants. It was not necessary to calculate the sample size formula as the researchers analyzed the total number of consultations in a psychiatric unit during the study period.

\subsection{Measures}

Data were collected via a questionnaire, which included questions regarding the demographic characteristics of the patients, such as age, gender, education level, job, and marital status. Variables such as ward of requesting consultation, psychiatric diagnosis, and reason 
for referral for psychiatric consultation, treatment interventions, and follow-up rates were also assessed. Psychiatric clinical interviews were conducted according to the fourth revised diagnostic criteria of the diagnostic and statistical manual of mental disorders (DSM-IV-TR). In addition to these interviews, patient's precise medical information was obtained and used in making the final diagnosis. In order to obtain further information regarding patient's medical status, physicians studied their medical records if necessary, the psychiatrist spoke with ward nurses, and, to ensure completeness of information, they discussed each patient's medical history with their family. In some cases, psychiatrists directly spoke with the patient's physician to determine the reasons for referral. After collecting the necessary mental-physical information and conducting a careful mental examination, a physical examination was also carried out if required.

\subsection{Statistical Analysis}

Data analysis was conducted using statistical package for the social sciences software and descriptive statistics.

\section{Results}

A total of 1688 consultations were conducted by the Department of Psychosomatics. Approximately 71.3 \% (n $=1,204$ ) were conducted in Imam Khomeini Hospital and 26.8\% ( $n=484)$ were carried out in Bu Ali Sina Hospital. Of the consultations, $34 \%$ were requested by the emergency ward through a physician, and the remaining consultations were of a non-emergency nature. The data from the two hospitals were analyzed together, and the results are reported below.

\subsection{Demographic Characteristics}

The demographic characteristics of the participants are shown in Table 1. Frequency distribution, according to age group, showed that most patients $(n=393 ; 23.3 \%)$ referred for psychiatric consultation were aged 20 - 29 years. Gender frequency distribution showed that 935 (55.4\%) of the participants were female and 745 (44.1\%) were male. In most cases, the level of education and job were not reported and a greater number of those who provided this information had a diploma and higher degree (19.9\%) as well as were self-employed. The frequency distribution of marital status indicated that a greater number of married than unmarried individuals were referred for psychiatric consultation.

\begin{tabular}{|c|c|}
\hline Subject & No. $(\%)($ Total $=1688)$ \\
\hline \multicolumn{2}{|l|}{ Age } \\
\hline Under ten years old & $2(0.1)$ \\
\hline $10-19$ & $146(8.6)$ \\
\hline $20-29$ & $393(23.3)$ \\
\hline $30-39$ & $290(17.2)$ \\
\hline $40-49$ & $246(14.6)$ \\
\hline $50-59$ & $257(15.2)$ \\
\hline Upper 60 & $304(18.00)$ \\
\hline Not specified & $50(3.00)$ \\
\hline \multicolumn{2}{|l|}{ Gender } \\
\hline Male & $745(44.1)$ \\
\hline Female & $935(55.4)$ \\
\hline Not specified & $8(0.5)$ \\
\hline \multicolumn{2}{|l|}{ Education } \\
\hline Illiterate and primary & $313(18.5)$ \\
\hline Three & $155(9.1)$ \\
\hline Guidance diploma, & $335(19.9)$ \\
\hline Upper diploma & $107(6.3)$ \\
\hline Bachelor, MSc, PhD & $5(0.29)$ \\
\hline Not specified & $773(46.0)$ \\
\hline \multicolumn{2}{|l|}{ Job } \\
\hline Unemployment & $91(5.4)$ \\
\hline Worker & $37(2.2)$ \\
\hline Free & $204(12.1)$ \\
\hline Employee & $89(5.3)$ \\
\hline House worker & $281(16.6)$ \\
\hline Educate & $123(7.3)$ \\
\hline Retired & $61(3.6)$ \\
\hline Not specified & $802(47.5)$ \\
\hline \multicolumn{2}{|l|}{ Marital status } \\
\hline Single & $246(14.6)$ \\
\hline Married & $832(49.3)$ \\
\hline Divorced & $40(2.4)$ \\
\hline Widow & $43(2.5)$ \\
\hline Not specified & $527(31.2)$ \\
\hline
\end{tabular}

\subsection{Source of Referral}

Table 2 shows that the majority of consultation cases were referred from the emergency wards (34\%), followed by the neurosurgery (14.2\%), and internal medicine (14.2\%) wards. 


\begin{tabular}{|c|c|c|c|}
\hline Ward & No. $(\%)($ Total $=1688)$ & Mount of Hospitalization $($ Total $=\mathbf{3 2 4 7 4})$ & Consultation Admission \\
\hline Emergency & $568(34.0)$ & 6202 & $9.15 \%$ \\
\hline Internal medicine ward ${ }^{a}$ & $241(14.2)$ & 4262 & $5.6 \%$ \\
\hline General surgery & $149(8.8)$ & 3406 & $4.37 \%$ \\
\hline Neurosurgery & $240(14.2)$ & 1491 & $16.9 \%$ \\
\hline Oncology & $79(4.6)$ & 2417 & $3.26 \%$ \\
\hline Gynecology/obstetrics & $89(5.3)$ & 4994 & $1.78 \%$ \\
\hline Urology & $14(0.8)$ & 2483 & $0.56 \%$ \\
\hline Orthopedic & $121(7.2)$ & 2440 & $4.95 \%$ \\
\hline Intensive care unit & $58(3.4)$ & 1763 & $3.63 \%$ \\
\hline ENT & $23(1.3)$ & not check & not check \\
\hline Psychiatry & $6(0.4)$ & 196 & $3.06 \%$ \\
\hline Not specified & $100(5.9)$ & Unable to check & Unable to check \\
\hline
\end{tabular}

${ }^{\mathrm{a}}$ Internal ward include: Rheumatology, pulmonary, dialysis, digestion department.

\subsection{Reason for Consultation}

As shown in Table 3, psychological assessment (26.8\%) was mentioned as the most common reason for requesting a psychiatric consultation. Suicide (20.7\%), methadone replacement therapy (15.4\%), and psychiatric disorder (11.4\%) were also common reasons. Crisis intervention ( $0.8 \%)$ was associated with the lowest rates of referral with specific reasons. In $0.7 \%$ of cases, the reason for referral was not specified.

\begin{tabular}{ll}
\hline Table 3. Reason of Consulting & \\
\hline Reason of Consulting & No. $(\%)(\mathbf{n}=\mathbf{1 6 8 8})$ \\
\hline Psychological assessment & $453(26.8)$ \\
\hline Suicide & $350(20.7)$ \\
\hline Methadone replacement therapy & $260(15.4)$ \\
\hline Psychiatric disorders & $192(11.4)$ \\
\hline Behavioral changes and aggression & $187(11.1)$ \\
\hline Psychotherapy & $78(4.7)$ \\
\hline Not justified Physical symptoms & $78(4.7)$ \\
\hline Delirium & $31(1.8)$ \\
\hline Sleep disorder and Insomnia & $22(1.3)$ \\
\hline Crisis intervention & $14(0.8)$ \\
\hline Reason of consulting not mentioned & $12(0.7)$ \\
\hline Lack of cooperation in treatment & $11(0.6)$ \\
\hline
\end{tabular}

\subsection{Psychiatric Diagnosis}

Mood disorder was the most common psychiatric diagnosis (22.3\%) made by CLP in psychiatric consultation. This was followed by substance-related disorder (12.3\%), adjustment disorder (9.5\%), and anxiety disorder (7.6\%). A total of 165 (9.9\%) patients had no psychiatric disorder, while $22(3.1 \%)$ patients required further diagnostic consultation (Table 4). Frequencies of comorbid diagnoses, based on the DSM-IV-TR, are shown in Table 4. Two comorbid diagnoses of axis I were identified in $8.2 \%$ of cases.

\subsection{Therapeutic Intervention and Follow-Up}

In 985 (58.4\%) of the consultation cases, psychiatrists prescribed a pharmacological treatment approach, while 286 patients (16.9\%) received psychotherapy and pharmacological treatment, and psychotherapy was prescribed for $251(14.9 \%)$ of patients. There was no treatment intervention in 166 (8.9\%) cases. Almost 90\% of patients required further visits, which were conducted during hospitalization or continued after discharge (Table 5).

\section{Discussion}

The current study assessed the frequency of psychiatric diagnoses in consultations conducted by a CLP service in Sari, Northern Iran between 2014 - 2015. The sample used in the present study was 1688 consultations, which was relatively large compared to the majority of similar previous studies conducted in Iran, for example, studies in which the sample sizes were 503, 600, and 382 cases, respectively $(11,24,30)$. The degree of success of CLP intervention depends on several variables, such as how the service is established, the experience of the consultation team members, 


\begin{tabular}{|c|c|}
\hline Psychiatric Diagnosis & No. $(\%)($ Total $=1444)$ \\
\hline \multicolumn{2}{|l|}{ Psychiatric single-diagnosis consultations } \\
\hline Mood disorder & $377(22.3)$ \\
\hline Substance related disorder & $207(12.3)$ \\
\hline Without psychiatric disorder & $167(9.9)$ \\
\hline Adjustment disorder & $160(9.5)$ \\
\hline Anxiety disorder & $129(7.6)$ \\
\hline Organic disorder (delirium) & $89(5.3)$ \\
\hline Somatoform disorder & $80(4.7)$ \\
\hline Personality disorder + suicide & $57(3.4)$ \\
\hline Psychotic disorder & $53(3.1)$ \\
\hline Relational problem & $30(1.8)$ \\
\hline Need to further diagnostic evaluation & $22(1.3)$ \\
\hline Consultation grief and crisis & $18(1.2)$ \\
\hline Psychotic disorder due to GMC & $12(0.7)$ \\
\hline Dementia & $9(0.5)$ \\
\hline MR(Mental Retardation) & $8(0.5)$ \\
\hline Drug side effects & $7(0.4)$ \\
\hline Fibromyalgia or tension headache & $6(0.4)$ \\
\hline Tic disorder & $4(0.2)$ \\
\hline Impulse control disorder & $4(0.2)$ \\
\hline Missing system & $3(0.2)$ \\
\hline Reproductive disorder & $2(0.1)$ \\
\hline \multicolumn{2}{|l|}{ Multiple psychiatric diagnosis in consultation } \\
\hline Comorbidity of two disorders in axis I & $139(8.2)$ \\
\hline $\begin{array}{l}\text { A diagnosis of axis I + substance related } \\
\text { disorder }\end{array}$ & $46(2.7)$ \\
\hline Axis I+ personality disorder (axis II) & $41(2.4)$ \\
\hline Comorbidity of three diagnosis in axis I,II & $18(1.1)$ \\
\hline \multicolumn{2}{|l|}{ Table 5. Treatment Approach and Follow Up } \\
\hline Treatment Approach and Follow Up & No. $(\%)($ Total $=1688)$ \\
\hline \multicolumn{2}{|l|}{ Treatment approach } \\
\hline Pharmacological therapy & $985(58.4)$ \\
\hline Psychotherapy & $286(16.9)$ \\
\hline Pharmacological therapy + psychotherapy & $251(14.9)$ \\
\hline Not treatment intervention & $166(9.8)$ \\
\hline \multicolumn{2}{|l|}{ Follow up } \\
\hline Yes & $1469(87.0)$ \\
\hline No & $212(12.6)$ \\
\hline Not specified & $7(0.4)$ \\
\hline
\end{tabular}

uniformity of intervention, and attempts to establish effective pathways of communication with specialists in internal medicine (23).

In the present study, the consultation rate was $4.06 \%$, compared to the $0.9 \%$ rate observed in a previous study in Imam Khomeini Hospital (11). This is consistent with the fact that the development of CLP services has been increasing in recent decades $(21,22,27)$. The increased rates of consultations in Imam Khomeini Hospital also represented a significant growth in CLP services compared to previous years. This growing trend is due to the positive attitudes and practice of physicians toward CLP in the teaching hospitals of Mazandaran. Successful psychiatric education and psychiatry practice also plays an important role in the formation of a positive attitude (31). Another important consideration, with regard to CLP development in Imam Khomeini Hospital, is that there was previously only one psychiatrist at this institution working part-time. However, now, three science committee psychiatrists are settled, and a psychosomatic ward with the capacity to hospitalize individuals with psychosomatic disorders was launched nearly 18 months ago.

In our study, the rate of requested psychiatric consultations was higher for females than for males. Most of the patients were aged 20 - 29 years, which is similar to the findings of most previous studies $(9,30,32,33)$. The present study showed that the majority of consultations were requested by emergency wards. The fact that it was conducted in a university general hospital located in a city center, that it is a main referral center for traumatic patients, and that patients attempting suicide are often initially taken to this hospital may be convincing explanations of the high rates of psychiatric referrals from the emergency ward. In their study, Ghanbari Jolfaee et al. found the opposite; the emergency ward was associated with the lowest rate of referral for psychiatric consultation, although it appears that this finding cannot be explained (34). The emergency ward is the site of patients' primary contact with the hospital, and the psychiatric consultant must make critical decisions regarding diagnosis and management (3). In contrast, other studies have shown that the internal medicine ward is the most common source of psychiatric referrals $(2,32,34)$.

The most common reason for psychiatric referral in our study was for psychological assessment, which is in accordance with the results of most previous studies $(11,34$, 35). It has been stated that psychological assessment is not a helpful and accurate reason, due to the fact that physicians with other majors have spent only a brief amount of time in psychiatric education, 1 and 3 months in internship and as externs, respectively; therefore, they are not familiar with psychiatric disorders and issues $(36,37)$. In some 
studies, psychiatric consultations were requested in cases of suicide attempts (3) or when physicians were unable to find a medical cause for a disease (31). In another study, depression was the most prevalent reason given for requesting a psychiatric consultation (2).

The most prevalent psychiatric diagnosis in the present study was mood disorder. Substance-related disorder, adjustment disorder, and anxiety disorder were at the core of CLP action in the two general hospitals assessed, while reproductive disorder was associated with the lowest rate of a psychiatric diagnosis made by CLP. It has been shown that patients in teaching hospitals with a psychiatric ward were more likely to have a psychiatric consultation than patients in other types of hospitals (19). Some studies have declared that mood disorders and organic mental disorders were the group psychiatric diagnoses that were most frequently encountered $(2,13$, $24,27)$. However, several Iranian studies have shown that delirium was the most common diagnosis in psychiatric consultations $(11,30)$, which was likely due to the fact that psychiatrists were only monitoring the performance of psychiatry assistants part-time, and the assistants spent only a 3-month rotational period in the hospital evaluated. The delirium diagnosis also showed that it was considered that a greater number of patients in emergency care and agitated patients required a psychiatric consultation (11). The rate of anxiety disorder observed in our study is significantly higher than that discussed in previous reports $(2,17,24)$. Our study showed that, despite a high prevalence of psychiatric disorders in the gynecology and dialysis wards $(38,39)$, few psychiatric consultations were requested by specialists. Several studies have reported that non-psychiatrist physicians often do not recognize psychiatric disorders in their patients, and that this leads to inappropriate psychiatric referrals $(6,31)$. In addition, it is possible that these physicians pay less attention to the psychosocial aspects of psychiatric disorders, which is due to a lack of knowledge and lack of education in this regard $(31,33)$. A crucial issue is that of what happens to those patients whose psychiatric illness remains undetected (18), as it has been shown that mood disturbance may hinder recovery from physical illness, and adversely influences mortality rates. Furthermore, in some cases, physicians may diagnose a psychiatric disorder, however, they prefer the patient to remain under treatment and they don't consider treatment in the period of the patients' hospitalization (5).

In over $15 \%$ of the psychiatric consultations in the present study, we determined multiple psychiatric disorders, of which two comorbid diagnoses of axis I was in the majority (8.2\%). In addition, psychiatrists detected another psychiatric diagnosis, such as axis I along with axis II disor- ders (personality disorders), in $2.4 \%$ of consultations.

The treatment approaches used in patients in the present study was based more on pharmacological interventions than on psychotherapy alone. This was likely due to the prescribing psychopharmacological intervention is simple, and also more patients adhere to such treatments. Psychiatrists considered psychiatric interventions in 16.9\% of cases. Although supportive psychotherapy and crisis intervention was carried out, it was not recorded, which may primarily be due to the fact that these interventions are not covered by medical insurance.

Following initial psychiatric consultation, $87 \%$ of the patients were assigned to follow-up and to receive continued psychiatric care. The provision of follow-up contact in the case of diagnostic or therapeutic consultation affords the opportunity to check a patient's status (25).

One limitation of the present study is related to the lack of precision in accurate recording of some psychiatric consultation data in the form of counseling. Although we attempted to put a copy of the conducted consultation in each respective file, it may be missed, due to forgetfulness or because the physician is not thorough when examining the file contents. Another important limitation of the current study was that the Imam Khomeini Hospital only has educational wards, however, Bu Ali Hospital has both educational and therapeutic wards, which its educational ward is consisted of neurological and various wards of pediatrics. In Bu Ali Hospital, given that there was no pediatrics specialty in the consultation-liaison psychiatry group, requested psychiatric consultation rate was less than the Imam Khomeini Hospital. We propose that further studies should be performed with regard to how CLP services can improve their capacity for recognition of psychiatric disorders and their treatment in general hospitals.

\subsection{Conclusion}

Although there is a high prevalence of psychiatric comorbidities in patients in general medical hospitals, the lack of medical specialists and nursing staff may mean that psychological distress goes unrecognized, with a consequent delay in appropriate interventions. The establishment of CLP services in each hospital is an important and useful implementation. In addition, appropriate psychiatric consultation can ensure that the majority of patients with psychiatric disorders can be maintained in the ward to which they have been admitted, and can receive treatment interventions. In order to ensure an effective performance, psychiatric liaison staff should be trained in a multiplicity of consulting roles and should improve their skills in addressing the treatment of inpatients and outpatients. Further, non-psychiatric physicians should increase their knowledge of, and attitude toward, the psychosocial 
aspects of medical disorders in order to make appropriate psychiatric referrals if required. In addition, it is proposed that consultation liaison service contains pediatrics and adults psychiatrists.

\section{Acknowledgments}

We wish to express our thanks to the medical and nursing staffs and consultation liaison psychiatrists collaborated in these consultations. We sincerely appreciate Mazandaran University of Medical Sciences for providing funds for this project.

\section{Footnotes}

Authors' Contribution: Forouzan Elyasi contributed to the conception of the work and definition of intellectual content, analyzed the data, and edited the manuscript literary. Marzieh Azizi Wrote the primary manuscript prepared the manuscript and edited the manuscript literary. Sina Sabourian Joubari and Seyyed Hessam Mirani gathered the data.

Declaration of Interest: None Declared.

Funding/Support: We sincerely appreciate Mazandaran University of Medical Sciences and Student Research Committee for providing funds for this project (Grant number: 96-107).

\section{References}

1. Mustafa MA, Fawzy AR. Psychiatric morbidity and consultations among medical and surgical inpatients in a general hospital in Kuwait. Arab J Psychiatry. 2009;20(2):87-108.

2. Karasu TB, Plutchik R, Steinmuller RI, Conte H, Siegel B. Patterns of psychiatric consultation in a general hospital. Hosp Community Psychiatry. 1977;28(4):291-4. [PubMed: 844820].

3. Sobel SN, Munitz H, Karp L. Psychiatric consultations in two Israeli general hospitals. Gen Hosp Psychiatry. 1988;10(4):298-304. [PubMed: 3417132].

4. Shevitz SA, Silberfarb PM, Lipowski ZJ. Psychiatric consultations in a general hospital. A report on 1,000 referrals. Dis Nerv Syst. 1976;37(5):295-300. [PubMed: 1261347].

5. Maguire GP, Julier DL, Hawton KE, Bancroft JH. Psychiatric morbidity and referral on two general medical wards. BrMed J.1974;1(5902):26870. [PubMed: 4818184]. [PubMed Central: PMC1633152].

6. Krautgartner M, Alexandrowicz R, Benda N, Wancata J. Need and utilization of psychiatric consultation services among general hospital inpatients. Soc Psychiatry Psychiatr Epidemiol. 2006;41(4):294-301. doi: 10.1007/s00127-005-0025-z. [PubMed: 16479327].

7. Laugharne R, Flynn A. Personality disorders in consultationliaison psychiatry. Curr Opin Psychiatry. 2013;26(1):84-9. doi: 10.1097/YCO.0b013e328359977f. [PubMed: 23187085].

8. Bronheim HE, Fulop G, Kunkel EJ, Muskin PR, Schindler BA, Yates WR, et al. The academy of psychosomatic medicine practice guidelines for psychiatric consultation in the general medical setting. The academy of psychosomatic medicine. Psychosomatics. 1998;39(4):S830. [PubMed: 9691717].
9. Beyraghi N, Shams J, Mohajer M, Bahreinian AM. [Psychiatric consultation in Taleghani hospital in 2002]. Pajouhesh Dar Pezeshki. 2004;28(2):141-4. Persian.

10. Druss BG, Walker ER. Mental disorders and medical comorbidity. Synth Proj Res Synth Rep. 2011;(21):1-26. [PubMed: 21675009].

11. Hosseini SH, Mortazavi M. [Frequency of referral rate and psychiatric diagnoses in Sari Imam Khomeini hospital during 2008 and 2009]. Mazandaran Univ Med Sci J. 2010;20(80):63-8. Persian.

12. Masters GA, Baldessarini RJ, Ongur D, Centorrino F. Factors associated with length of psychiatric hospitalization. Compr Psychiatry. 2014;55(3):681-7. doi: 10.1016/j.comppsych.2013.11.004. [PubMed: 24387922].

13. Clarke DM, Smith GC. Consultation-liaison psychiatry in general medical units. Aust N Z J Psychiatry. 1995;29(3):424-32. doi: 10.3109/00048679509064950. [PubMed: 8573045].

14. Seltzer A. Prevalence, detection and referral of psychiatric morbidity in general medical patients. J R Soc Med. 1989;82(7):410-2. [PubMed: 2585427]. [PubMed Central: PMC1292206].

15. Rothenhausler HB. [Mental disorders in general hospital patients]. Psychiatr Danub. 2006;18(3-4):183-92. German. [PubMed: 17099609].

16. Fava GA, Pavan L. Consultation psychiatry in an Italian general hospital: a report on 500 referrals. Gen Hosp Psychiatry. 1980;2(1):35-40. [PubMed: 7380247].

17. Bourgeois JA, Wegelin JA, Servis ME, Hales RE. Psychiatric diagnoses of 901 inpatients seen by consultation-liaison psychiatrists at an academic medical center in a managed care environment. Psychosomatics. 2005;46(1):47-57. doi: 10.1176/appi.psy.46.1.47. [PubMed: 15765821].

18. Ndetei DM, Khasakhala LI, Kuria MW, Mutiso VN, Ongecha-Owuor FA, Kokonya DA. The prevalence of mental disorders in adults in different level general medical facilities in Kenya: A cross-sectional study. Ann Gen Psychiatry. 2009;8:1. doi: 10.1186/1744-859X-8-1. [PubMed: 19144164]. [PubMed Central: PMC2631009].

19. Kuhn WF, Bell RA, Frierson RL, Lippmann SB. Consultative psychiatry in both private and public general hospitals. Gen Hosp Psychiatry. 1986;8(4):236-40. [PubMed: 3744030].

20. Lipowski ZJ. Review of consultation psychiatry and psychosomatic medicine. 3. Theoretical issues. Psychosom Med. 1968;30(4):395-422. [PubMed: 4876595].

21. Grover S. State of consultation-liaison psychiatry in india: Current status and vision for future. Indian J Psychiatry. 2011;53(3):202-13. doi: 10.4103/0019-5545.86805. [PubMed: 22135437]. [PubMed Central: PMC3221175].

22. Diefenbacher A, Strain JJ. Consultation-liaison psychiatry: Stability and change over a 10-year-period. Gen Hosp Psychiatry. 2002;24(4):249-56. [PubMed: 12100835].

23. De Giorgio G, Quartesan R, Sciarma T, Giulietti M, Piazzoli A, Scarponi L, et al. Consultation-Liaison Psychiatry-from theory to clinical practice: An observational study in a general hospital. BMC Res Notes. 2015;8:475. doi: 10.1186/s13104-015-1375-6. [PubMed: 26403798]. [PubMed Central: PMC4582719]

24. Arbabi M, Laghayeepoor R, Golestan B, Mahdanian A, Nejatisafa A, Tavakkoli A, et al. Diagnoses, requests and timing of 503 psychiatric consultations in two general hospitals. Acta Med Iran. 2012;50(1):5360. [PubMed: 22267380].

25. Leentjens AF, Boenink AD, van der Feltz-Cornelis CM. Can we increase adherence to treatment recommendations of the consultation psychiatrist working in a general hospital? A systematic review. J Psychosom Res. 2010;68(3):303-9. doi: 10.1016/j.jpsychores.2009.07.006. [PubMed: 20159218].

26. Wood R, Wand AP. The effectiveness of consultation-liaison psychiatry in the general hospital setting: A systematic review. J Psychosom Res. 2014;76(3):175-92. doi: 10.1016/j.jpsychores.2014.01.002. [PubMed: 24529036]. 
27. Grant JE, Meller W, Urevig B. Changes in psychiatric consultations over ten years. Gen Hosp Psychiatry. 2001;23(5):261-5. [PubMed: 11600167].

28. Smaira SI, Kerr-Correa F, Contel JO. Psychiatric disorders and psychiatric consultation in a general hospital: A case- control study. Rev Bras Psiquiatr. 2003;25(1):18-25. [PubMed:12975675].

29. Marcus SE, Pincus HA, Goldman HH, Wallen J. Factors associated with the use of psychiatric consultations in short-term general hospitals. Psychosom Med.1987;49(5):508-22. [PubMed:3671638].

30. Semnani Y, Mostofian M. [Psychiatric consultation in Imam Hossein hospital]. Daneshvar Med Sci J. 2007;14(68):37-42. Persian.

31. Zarghami M, Farnia S, Khalilian AR, Amirian T. Study of attitudes and practice of physicians regarding consultation-liaison psychiatry in teaching hospitals of mazandaran, Iran. Iran J Psychiatry Behav Sci. 2014;8(2):38-43. [PubMed: 25053955]. [PubMed Central: PMC4105602].

32. Fard K, Ehsan manesh M. [Frequency of psychiatric diagnosis in patients referred for psychiatric consultation in a General Hospital]. Thoughts and behavior. 2005;11(1):6-14. Persian.

33. Zarghami M, Nateghi G, Khalilian A, Tirgari A, Salimi H. [Psychi- atric disorders in refferd to educational hospital's general clinics of Mazandaran University of Medical Science in 1997]. Mazandaran Univ Med Sci J. 2002;12(36):33-40. Persian.

34. Ghanbari Jolfaee A, Nasr Esfahania M. Trends of psychiatric consultation in Rasoul Akram Hospital. Iran J Psychiatry Clin Psychol. 2012;18(1):1-6.

35. Malhotra S. Liaison psychiatry in general hospitals. Indian J Psychiatry. 1984;26(3):264-73. [PubMed: 21965998]. [PubMed Central: PMC3011251].

36. Ministry of Health TAME. Educational curriculum of general medical course In: Sciences MUOM. [cited 2017-02-05]. Available from: http:// medicine.mazums.ac.ir/2010.

37. Ministry of Health TAME. Educational curriculum of general medical course. In: science Tuom. [cited 2017-02-05]. Available from: http:// medicine.tums.ac.ir/2016.

38. Levenson JL. The American psychiatric publishing textbook of psychosomatic medicine: Psychiatric care of the medically ill. American Psychiatric Pub; 2011.

39. Lloyd G, Guthrie E. Handbook of liaison psychiatry. Cambridge University Press; 2007. doi: 10.1017/CBO9780511543975. 